\title{
METHODS OF CALCULATING ADDED WATER IN MILK.
}

\author{
By LESLIE J. HARRIS.
}

IN a previous communication dealing with the calculation of added water in milk (ANaLYst, 1918, 43, 345) I proposed the use of the formula,

$$
\mathrm{W}=100-\frac{10,000 \mathrm{~N}}{8 \cdot 5(100-\mathrm{F})+3 \mathrm{~N}},
$$

as being specially applicable to samples containing an excess of cream. By this formula the added water is calculated on the assumption that the original milk contained the minima of both fat and solids-not-fat, it being postulated that an accumulation of tat from $F$ to $F^{\prime}$ is accompanied by a diminution of solids-not-fat from $N$ to $N \times \begin{aligned} & 100-F^{\prime} \\ & 100-F\end{aligned}$

The formula above involves a rather long and unwieldy calculation. This may be obviatiod by having resource to one of the methods below:

1. Calcuiation of Solids-not-Fat in the Frat-Free Milk.-If the sample contains $\mathrm{N}$ p:r cent. of solids-not-fat and $\mathrm{F}$ per cent. of fat, the amount of solids-not-fat in the fat-free milk will be $\frac{\mathrm{N} \times 100}{100-\mathrm{H}^{2}}$, and from this we may determine the extraneous water by reference to the tabla below.

For example, " milk" containing 10 per cent. of fat and 3.88 per cent. of solidsnot-fat, contuins in the fat-free portion $3.88 \times \frac{100}{90}=4.31$ per cent. of solids-not-fat, which is seen to be equivalent to a mixture of 50 parts of water with 50 parts of milk of the minimum standard. 


\section{HARRIS : METHODS OF CALCULATING ADDED WATER IN MILK}

In the table, the values for solids-not-fat in the fat-free milk are calculated from

$$
\frac{(100-\text { added water })}{100} \times 8.5 \times 100-\frac{100}{\frac{(100-\text { added water })}{100} \times 3}
$$

Mathematical reasoning will show that the results obtained from this expression are identical with those given by the formula.

\begin{tabular}{|c|c|c|c|c|c|}
\hline Added Water. & $\begin{array}{c}\text { Solids-not-Fat } \\
\text { in Fat-Free } \\
\text { Milk. }\end{array}$ & $\begin{array}{c}\text { Corresponding } \\
\text { to Solids-not- } \\
\text { Fat in Milk of } \\
\text { Minimun } \\
\text { Standard. }\end{array}$ & Added Water. & $\begin{array}{c}\text { Solids-not-Fat } \\
\text { in Fat-Free } \\
\text { Milk. }\end{array}$ & $\begin{array}{l}\text { Corresponding } \\
\text { to Solids-not- } \\
\text { Fat in Milk of } \\
\text { Minimum } \\
\text { Standard. }\end{array}$ \\
\hline $\begin{array}{c}\text { Per Cent. } \\
0 \\
1 \\
2 \\
3 \\
4 \\
5 \\
6 \\
7 \\
8 \\
9 \\
10 \\
11 \\
12 \\
13 \\
14 \\
15 \\
16 \\
17 \\
18\end{array}$ & 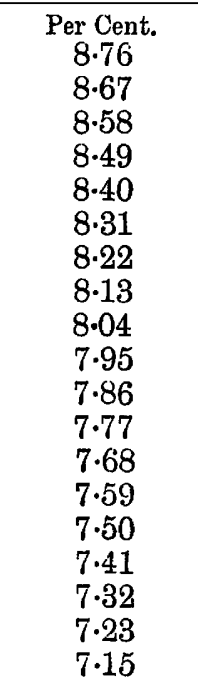 & $\begin{array}{c}\text { Per Cent. } \\
8 \cdot 50 \\
8 \cdot 41 \\
8 \cdot 33 \\
8.24 \\
8 \cdot 16 \\
8 \cdot 07 \\
7 \cdot 99 \\
7 \cdot 90 \\
7 \cdot 82 \\
7 \cdot 73 \\
7 \cdot 65 \\
7 \cdot 56 \\
7 \cdot 48 \\
7 \cdot 39 \\
7 \cdot 31 \\
7 \cdot 22 \\
7 \cdot 14 \\
7 \cdot 05 \\
6 \cdot 97\end{array}$ & $\begin{array}{c}\text { Per Cent. } \\
19 \\
20 \\
21 \\
22 \\
23 \\
24 \\
25 \\
26 \\
27 \\
28 \\
29 \\
30 \\
40 \\
50 \\
60 \\
70 \\
80 \\
90\end{array}$ & $\begin{array}{c}\text { Per Cent. } \\
7.06 \\
6.97 \\
6.88 \\
6.79 \\
6.70 \\
6.61 \\
6.52 \\
6.43 \\
6 \cdot 34 \\
6.26 \\
6.17 \\
6.08 \\
5.19 \\
4.31 \\
3.44 \\
2.57 \\
1.71 \\
0.85\end{array}$ & $\begin{array}{c}\text { Per Cent. } \\
6.88 \\
6.80 \\
6.71 \\
6.63 \\
6.54 \\
6.46 \\
6.37 \\
6.29 \\
6.20 \\
6 \cdot 12 \\
6.03 \\
5.95 \\
5.10 \\
4.25 \\
3.40 \\
2.55 \\
1.70 \\
0.85\end{array}$ \\
\hline
\end{tabular}

RuLE.-To find the "solids-not-fat in fat-free milk," multiply the solids-not-fat by $\frac{100}{100-\text { tat }}$; then find the corresponding figure for added water in Column I.

2. Alignment Chart.-Those who prefer a graphical method may make use of an alignment chart. The chart is read by means of a straightedge, stretched thread, or line engraved on a celluloid cursor, etc. The line is made to coincide with the values for fat and solids-not-fat on the respective scales, and the percentage of added water is read off at the intersection with the third scale. A chart of moderate size will indicate the added water with an accuracy of about 0.5 per cent.

The chart is constructed on the principle of a nomogram ("Traité de Nomographie." Par Maurice d'Ocagne. Paris, 1899). The left-hand scale is divided logarithmically in an upward direction from 1 to 100, the figures for fat being complementary, and therefore at a distance from the base proportional to $\log (100-F)$. The scale for solids-not-fat is divided directly on the same logarithmic scale, but in a negative sense. The third scale is midway between and parallel to those for fat 
and solids-not-fat. If, now, the upper half of this scale be divided logarithmically from 1 to 100, a straight line joining the points representing $F$ per cent. fat and $\mathrm{N}$ per cent. solids-not-fat will give a reading of $\frac{(100-F)}{N}$ in the central scale. By lowering the scale a distance log. 8.5 , the readings will be multiplied by 8.5 (i.e., $\left.8.5 \frac{(100-F)}{\bar{N}}\right)$; and by adding 3 units to each of the readings, converting these into their reciprocals, and multiplying by 10,000 , the readings will be of the value $\frac{10,000}{8 \cdot 5(100-\mathrm{F})}+3$. Since this is equivalent to $\frac{10,000 \mathrm{~N}}{8 \cdot 5(100-\mathrm{F})+3 \mathrm{~N}}$, the scale readings will now give the percentage of milk (of the minimum standard) in the mixture, the complementary numbers given in the chart therefore representing the added water.

A further use of the chart is to determine the change in composition of any sample of milk under the action of gravity or centrifugal force; for example, given the fat and total solids in whole milk to find the amount of solids-not-fat which the skim milk would contain, and the composition of the cream for any concentration of fat. For this purpose, all that is required is to place the straight edge coincident with the figure for fat and solids-not-fat, and rotate it around the point of intersection in the central scale until the new conditions are reached.

3. Slide Rule.-The principle of the alignment chart may be embodied in the form of a calculating rule. The reading for solids-not-fat on the lower scale is made to coincide with that for fat on the sliding scale; an arrow points to the percentage of added water on the upper scale. The rule is constructed in a precisely similar way to the alignment chart, except that the scale for added water is relatively twice as large, the percentages of added water being placed immediately opposite the figures for solids-not-fat in fat-free milk, as given in the table above. With the sliding scale in a given position, all possible corresponding combinations of fat with solids-not-fat are coincident.

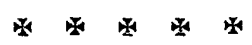

